Military Technical College Kobry El-Kobbah, Cairo, Egypt

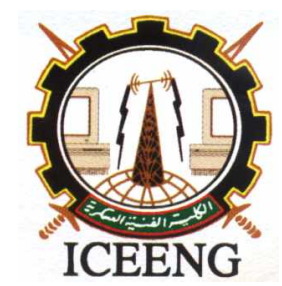

\author{
$6^{\text {th }}$ International Conference \\ on Electrical Engineering \\ ICEENG 2008
}

\title{
Energy Efficiency Initiatives In the Egyptian Power Sector
}

\author{
By \\ Ibrahim Yassin Mahmoud*
}

\section{$\underline{\text { Abstract: }}$}

The Egyptian Electricity sector has adopted strong measures in order to improve energy efficiency at supply and demand sides. In complementing these efforts, the Ministry of Electricity and Energy has started since 1999 implementing one of its important projects titled "Energy Efficiency Improvement and Greenhouse Gas Reduction" project for a duration of five years and budget of MUS\$ 5.9, financed by the Global Environment Facility (GEF), the United Nations Development Program (UNDP) and the Government of Egypt .

The overall objective of this project is to meet growing electricity demand through reliable, efficient and rational consumption patterns, thereby reducing greenhouse gas emissions, protecting environment while at the same time providing a sustainable alternative to capacity extension for meeting the demand.

The project includes three components:

- Loss Reduction, load shifting and load management of the Unified Power System of Egypt.

\section{Loss reduction:}

- Losses assessment

- Power factor correction

○ Optimal network planning

\section{Load Shifting:}

- Applying Time of Use (TOU) Tariffs

$\circ$ Load shifting in industrial sector

\section{- Energy Efficiency Market Support:}

- Conduct energy audits and encouraging ESCOs to implement energy efficiency projects

$\circ$ Applying efficient lighting programs 
- Applying standards and labels for efficient appliances

- Developing energy efficiency building code for new buildings

\section{$\checkmark$ Cogeneration.}

○ Promotion of cogeneration projects

\section{Major Project Achievements:}

- Due to the cooperation between the project and the Egyptian Electricity Holding Company, and implementation of project recommendation such as load redistribution, improving dynamic response of generating units, maximum use of reactive power generated by the power plants, power factor improvement through installation of capacitors banks at selected locations, the transmission losses have been reduced from $6.9 \%$ in year 1998 to $3.8 \%$ in year 2007.

- Diffusion of the use of efficient lighting systems and encouraging local manufacturing where 5 local manufacturers have already started their production (compact fluorescent lamps and electronic ballasts) and penetrated the market with the assistance of the project.

- Preparation of the energy efficiency specifications for three selected appliances (refrigerators, washing machines and air conditioners) and issuing a ministerial decree for the enforcement of these specifications and the sticked labels including the electricity consumption of each appliance to assist the consumer in selecting the most efficient ones.

- Preparing an energy efficiency code for the residential and commercial buildings to improve energy efficiency

- Preparing a data base for the big consumers with cooperation with electricity distribution companies to determine energy improvement actions to be taken by these consumers.

\section{Keywords:}

EEIGGR : Energy Efficiency Improvement and Greenhouse Gas Reduction Project 


\section{Introduction:}

Over the past ten years, electrical energy consumption and peak demand of Egyptian power system have been growing rapidly at rates of $8,6 \%$ and $8,1 \%$ respectively.

Meeting the ever increasing demand on electricity with a high degree of reliability and sustainability has been one of the main issues addressed by the strategy developed and implemented by the Ministry of Electricity and Energy.

In addition to this target, the Egyptian Electricity sector has adopted strong measures in order to improve energy efficiency at both the supply and demand sides, this resulted in reducing the overall average specific fuel consumption from $340 \mathrm{gm}$ to from $340 \mathrm{gm}$ to 225 gm of oil equivalent per kWh, reducing losses from $18 \%$ to 11.5\% in 2006/2007. Comparable efforts have been conducted on the demand side to effectively utilize the electrical energy.

\section{Energy Efficiency Improvement and Greenhouse Reduction Project:}

Among these efforts, the Ministry of Electricity and Energy has started since 1999 implementing one of its most important projects which is the" Energy Efficiency Improvement and Greenhouse Gas Reduction" project for a duration of five years and a total budget of MUS\$ 5.9, jointly financed by the Global Environment Facility (GEF), the United Nations Development Program (UNDP) with the support of the Government of Egypt.

The overall objective of this project is to meet suppressed and still growing electricity demand through reliable, efficient and rational consumption patterns, thereby reducing greenhouse gas emissions emanating from electric power generation, protecting the local environment while at the same time providing a sustainable alternative to capacity expansion as the sole method of meeting demand.

This objective is to be achieved through:

ßSupporting efficiency improvement and loss reduction in generation, transmission \& distribution of electric power.

BFacilitating adoption and implementation of energy conservation measures in residential, commercial and industrial sectors through initiation of energy audits, promotion financing and standard-setting activities.

BStimulating and guiding the private sector in the development of a capability for end use energy efficiency service planning, feasibility analysis, conceptual design and project implementation including the manufacture of energy efficient products.

BAssisting in international and regional transfer of technology and experience that could be instrumental in GHG emission reduction.

ßPromoting public and private sector investments in energy projects that are beneficial 
for the global environment.

The Ministry of Electricity and Energy, as the government implementing agency, has expressed its full commitment to sponsor the objectives and outputs of this project and to continue with their full implementation beyond the project completion where it is expected to reduce energy consumption by a total of 4.2 million tons of oil equivalent (MTOE)/year by the year 2010. These energy savings represent $11.8 \%$ of Egypt's total estimated energy use and are equivalent to 11.7 million tons of $\mathrm{CO} 2$ per year.

The project is expected to achieve its objectives through measures and activities classified under three main components:

- Loss Reduction and Load Shifting of the Egyptian Unified Power System

- Energy Efficiency Market Support.

- Promotion of Cogeneration.

The activities under these components are implemented by:

Ministry of Electricity and Energy:

- Egyptian Electricity Holding Company (EEHC);

- Organization for Energy Planning (OEP);

- Electricity Distribution Companies (ECs).

Ministry of Housing:

Housing \& Building Research Institute (HBRC)

Ministry of Industry and Technology Improvement:

Egyptian Organization for Standards (EOS)

\section{COMPONENT 1: Loss reduction, load shifting and Load Management in the UPS}

The target of this component is to reduce the transmission losses from $7 \%$ to $5 \%$ and introduce a time of use tariff to encourage load shifting, resulting in reducing energy consumption by 0.17 Million tons of oil equivalent and $\mathrm{CO} 2$ production by 0.48 million tons;

This target is achieved through:

- Improving Network Loss Measurement Capability

- Improve Dynamic Response for All Thermal Stations

- Reduce Transmission Losses through Network Analysis and Control Strategies

- Introduce Time of Use Tariff to Encourage Load Shifting

Improving Network Loss Measurement Capability:

$\ddot{y}$ In order to get accurate measurements of losses, the project has set a plan for calibration and maintenance of measuring devices. All measuring devices of the power sector have been calibrated using the high accuracy $(0.01 \%)$ calibrating equipment procured by the project. 
$\ddot{y}$ Holding training courses for engineers and technicians to improve their capability in the field of measurements, and calibration.

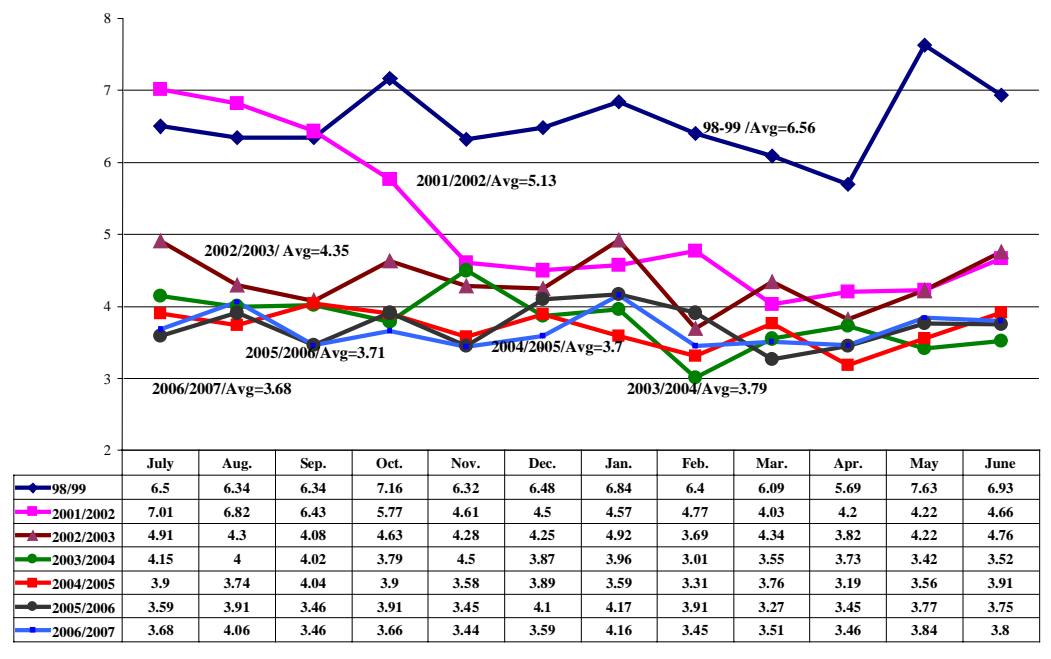

\section{Improve Dynamic Response of All Thermal Stations:}

Dynamic tests (ramp rates) of generating units with a capacity more than $100 \mathrm{MW}$ have been conducted, and engineers have been training to conduct and analyze these test.

Improve Transmission Losses through Network Analysis and Control Strategies

- Maximum use of reactive power of the generating units

- Improve the power factor through installation of capacitor banks at selected locations

- Optimization of network planning by using the up to date software program "Optimum Power Flow (OPF)"

As a result of these activities, the percentage network losses has deceased from $7 \%$ in year 1999 to $3.68 \%$ in year 2006/2007, achieving an energy saving in year 2006/2007 of 3.28 MTOE and a 9.58 of $\mathrm{CO} 2$ reduction.

\section{Introduce a TOU Tariff to Encourage Load Shifting.}

Sensitivity analysis study has been carried out to select the most appropriate scenarios for peak and off peak Time of use TOU tariff and presented to the decisions makers of EEHC for selection of the applied tariff.

\section{Load Shifting Application}

Load shifting is a proven technique adopted by electric utilities to reduce the peak load imposed on their systems associated with many technical and economic advantages.

Within its activities, the project carried field surveys to evaluate the load shifting potential at the industrial level.

As the cement industry is an energy intensive industry and represents a major share of 
the total consumption, it has been targeted as a promising sector for load shifting application where one of the cement companies has been selected for a load shifting pilot project implementation in order to shift part of the company's load during system peak period to system off-peak period.

\section{Beni Suef Cement Factory Case Study:}

The Beni Suef cement factory is located at Beni Suef city and has been in operation since 1993 with a capacity production of about 1.35 Million ton/year, the main installed loads of the company are: one kiln rated $5 \mathrm{MW}$, two cement mills rated $11 \mathrm{MW}$, two raw mills rated $10 \mathrm{MW}$ and one crusher rated $2 \mathrm{MW}$.

The contracted demand of the company is $30 \mathrm{MW}$ and the applied tariff is 11.34 $\mathrm{pt} / \mathrm{kWh}$. Based on contract, if the maximum load during system peak load period increases to over $105 \%$ of the monthly average load, a penalty of $2 \mathrm{LE}$ per $\mathrm{kW}$ increase is applied for the accounting month.

The load shifting application has been through stopping operation of 2 mills during system peak, hourly load profiles have been recorded before and after load shifting application and showed that the peak load of the company has decreased from $20 \mathrm{MW}$ to $16 \mathrm{MW}$ during system peak load.

Adjusted Load Profile for Economic Analysis

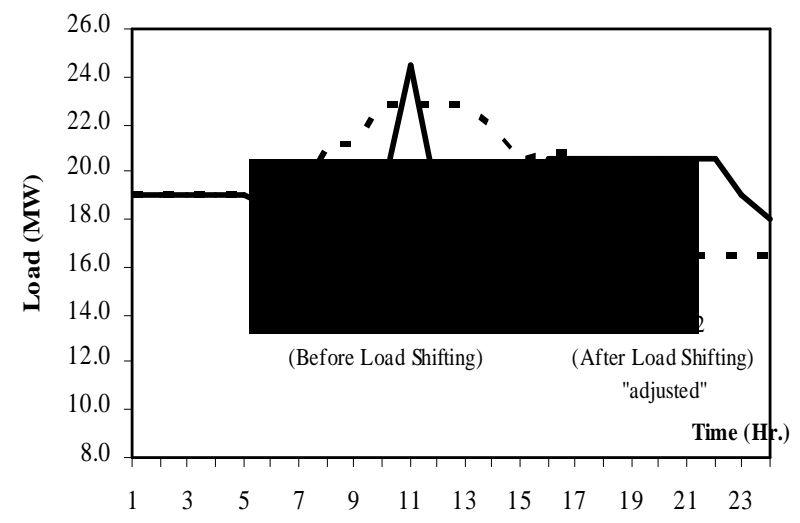

Some incentives approaches have been recommended for load shifting application: Bonus for load reduction, Bonus for load limit, Bonus for emergency cases (shortage of power), Time of use tariff (subjected to change of legislation)

These alternatives have been raised to decision makers for selection of the most appropriate one.

\section{Component 2: Energy Efficiency Market support}

The target of this component is to reduce $8.3 \%$ of the total energy consumption by the year 2010 resulting in reducing $\mathrm{CO} 2$ production by 8.25 million tons; through

- Energy Service Industry Support and Promotion

- Developing \& Applying Energy Efficiency Standards for Electrical Appliances 
- Developing \& Applying Energy Efficient Code for New Buildings

- Establishing an Energy Efficiency Center

\section{Energy Service Industry Support and Promotion:}

One of the major components of the project is energy efficiency business development through which the project has helped establish eight energy service companies (ESCOs). These companies include energy efficiency equipment suppliers, electromechanical contractors, utilities and consultants. Through the project, technical as well as business training was provided to these companies, which were supported and promoted through a programme for 200 partially financed energy audits, covering industrial and commercial sectors in all geographical regions of Egypt.

The audits were used to develop business opportunities for the companies, as well as an awareness campaign among the companies for energy efficiency. of the completed 200 audits, 19 projects have been implemented. The implemented projects are mainly related to power factor correction and high efficiency lighting, in addition to other technologies in smaller scales as shown in the figure.

Technologies used in Energy Audits

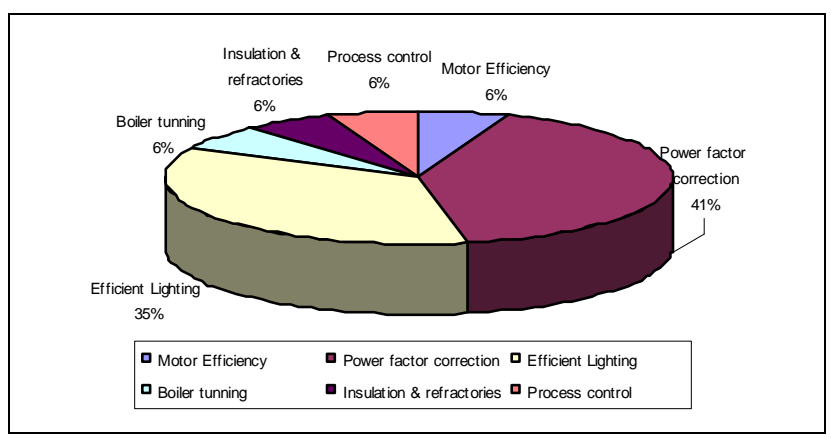

In Egypt, the share of lighting in energy consumption accounts is nearly $25 \%$ of the total energy sold in the country for the residential and commercial sectors, and $10 \%$ for the industrial sector, while the public lighting and government buildings lighting accounts for nearly $7 \%$.

Most of the lighting used in Egypt is low efficient and is largely responsible for the system peak time electricity production; in addition to high electricity bills, inefficient lighting has a negative impact on the environment by requiring the combustion of greater quantity of fossil fuel in power plants resulting in atmospheric pollutants shown to cause global warming, acid rain, smog etc....

Therefore the project has add a new activity for encouraging the use of the Compact Fluorescent Lamps and electronic ballasts to reduce the share of lighting in total energy consumption, selection has been based on the following:

- Simple technology, does not need special preparation 
- Simple and short pay back period

- High impact on energy saving and $\mathrm{CO} 2$ reduction

- A larger diffusion and a considerable increase of the CFL market Egypt.

- Increase of market size of compact fluorescent lamps from 245 thousands lamps in year 1999 to 4.4 million lamps in year 2007.

- Encourage the local manufacturing and offering new job opportunities.

- Decrease the price of CFLs from 35L.E in year 1999 to around 15 L.E in year 2007 for a good quality lamp due to the competition between manufacturers.
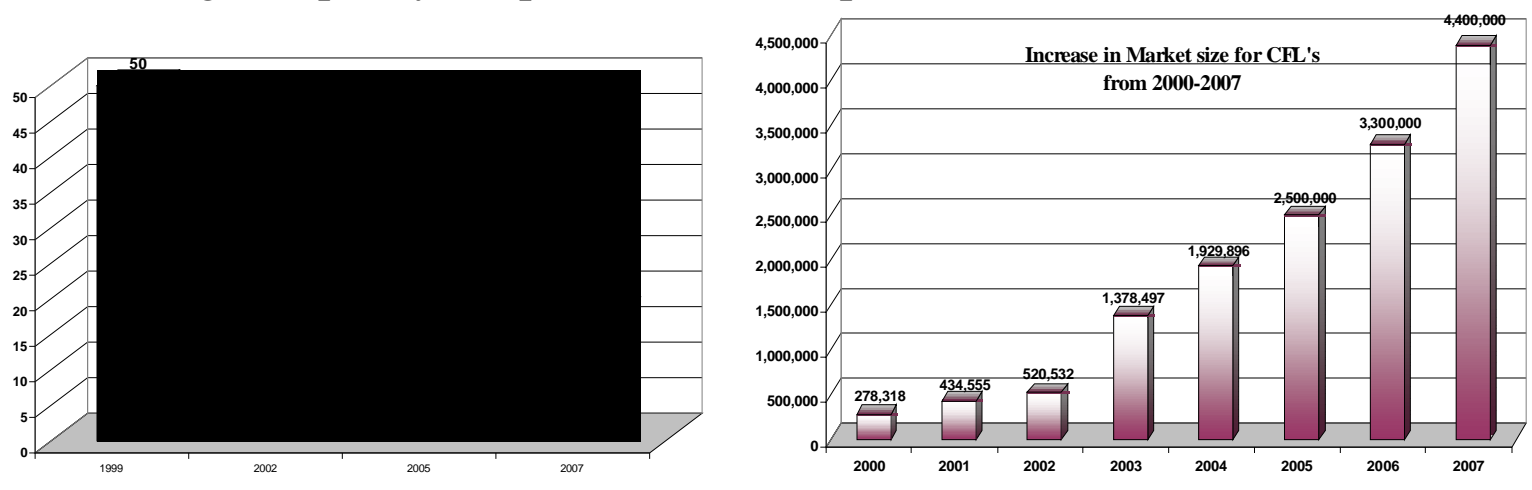

Achieving an energy saving of 0.778 MTOE and a CO2 reduction of 2.274 MTons EEIGGR has developed what is called an Egyptian Sustainable Loan Guarantee Mechanism (ESLGM) to enable access to finance to the ESCOs to finance their projects. EEIGGR has allocated a budget of 280,000 US\$ to this mechanism. The mechanism is being executed through a local financial institution. The Credit Guarantee Company (CGC) for small and medium size enterprises was selected as the financial institution which manages the mechanism. CGC is an Egyptian company which has been established by twelve public as well as private banks to enable access to finance for small and medium size enterprises.

For the projects which are executed through the mechanism, the customer will be requested to pay a down payment in the range of 10-20\% of the project cost (including cost of finance). The ESCO will be eligible to get a loan which will be $70 \%$ of the project cost minus the down payment. CGC will offer $100 \%$ credit guarantee to the loan. The guarantee will be effective as the ESCO sign the contract with the end user and present a bank document showing that the end user has already paid the down payment

The proposed financing mechanism is shown in the figure. The ESCO will be responsible for collecting its money from the customer and paying the loan payments to the bank after deducting their postponed profit. Since neither CGC nor the bank will deal directly with the customer, therefore CGC issues guidelines for the ESCO on the criteria to accredit the customer. CGC has subcontracted the Egyptian Consulting Center (ECC) to provide support to the ESCO in doing this credit study to the customer. 
Furthermore ECC will provide marketing support to the ESCOs.

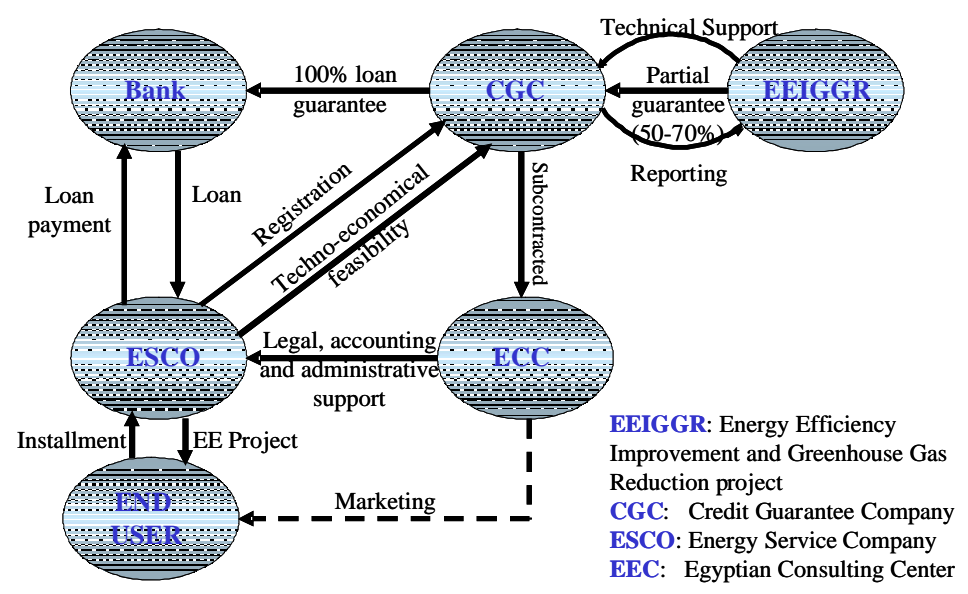

\section{EEIGGR” Project Initiatives to Promote the Use of Efficient Lighting in Egypt:}

As lighting represents a considerable share in the electrical energy consumed by residential, commercial, industrial sectors as well as public lighting; continuous efforts are to be exerted by all players contributing in reducing energy consumption through improvement of lighting systems. These include:

B The electricity companies, which have not starting yet implementation of the leasing program, for the diffusion of the CFLs over its customers.

B The decision makers and their role in adapting policies and regulations to the market condition (custom duty reduction, or incentive to encourage the adoption of efficient lighting systems).

ß The EEIGGR by itself and in cooperation with the NGOs, in increasing customer awareness on benefits of energy efficiency in general and efficient lighting particularly.

Within the project activities for promoting the use of efficient lighting equipment, many demonstration applications have been executed using CFL and electronic ballasts at different locations. Measurements have been carried out for comparing performance of magnetic and electronic ballasts over a period of 1000 hours and showed that in addition to the technical benefits, the percentage of energy saving is 33\%.

\section{National Plan for Improving Lighting Systems Used for Street Lighting:}

The Minister of Electricity and Energy has requested the project to prepare a study for implementation of a plan at the national level for improving the efficiency of lighting systems used for street lighting. The project with the assistance of the electricity companies has made a survey for these systems, results of which showed that more than 0.86 million incandescent lamps are mounted on 8 meter poles. Results also showed that 
the intensity of street lighting is very high when compared with international standards.

A techno economical study has been completed for replacing each incandescent lamp, $(100,150,200$ watts) by two compact fluorescent lamps of 23 watt each.

The plan is to replace these lamps within a period of 28 months representing the lifetime of the CFL and for 12 lighting hours per day.

The cost of the replacement is 44.2 ML.E.

The benefits gained are summarized as follows:

Ministry of Electricity and Energy:

Differed investments for production, transmission and distribution $=388.76$ M L.E.

Present Worth Value (P.W.V)

P. W. V of loss in revenues $=198.23$ M L.E.

P. W. V of reduced fuel consumption $=26.43$ M L.E.

Minister of Finance:

P. W. V of revenues $=154.03$ ML.E.

Minister of Petroleum:

P. W. V of reduced fuel consumption (International prices) $=121.44$ ML.E.

National Economy:

P. W. V of total revenues $=94.68$ ML.E.

Environmental Benefits:

$\mathrm{CO} 2$ reduction $=228259$ Tons

\section{Energy Efficiency Standards for New Equipment:}

There were no energy efficiency equipment or appliance standards in Egypt, the only standards for equipment pertain to health, safety or electrical technical compatibility. The objective of this activity is to develop and implement energy efficiency standards and labels to be applied first on a voluntary basis with public promotion. This provides time for manufacturers to assess market demand and to make necessary adjustments to product lines and production equipment. It also allows time for implementation details such as equipment testing, labeling systems, and promotional activities .The standards and labels was applied first on equipment selected based on the following criteria: degree of saturation, energy consumption intensity, growth rates and potential savings, where three equipment have been selected: refrigerators, air conditioners and automatic washing machines. Energy efficiency improvement options have been 
recommended for the selected appliances as follows:

Refrigerators: high efficient compressor, large condensing coil advanced control system, proper insulation thickness, high efficient fan motor.

Air conditioners: high efficient compressor, high efficient indoor and outdoor coils, advanced control systems alternative refrigerants, high efficient fan and fan motor. Washing machines: tube insulation, high efficient motor advanced control system.
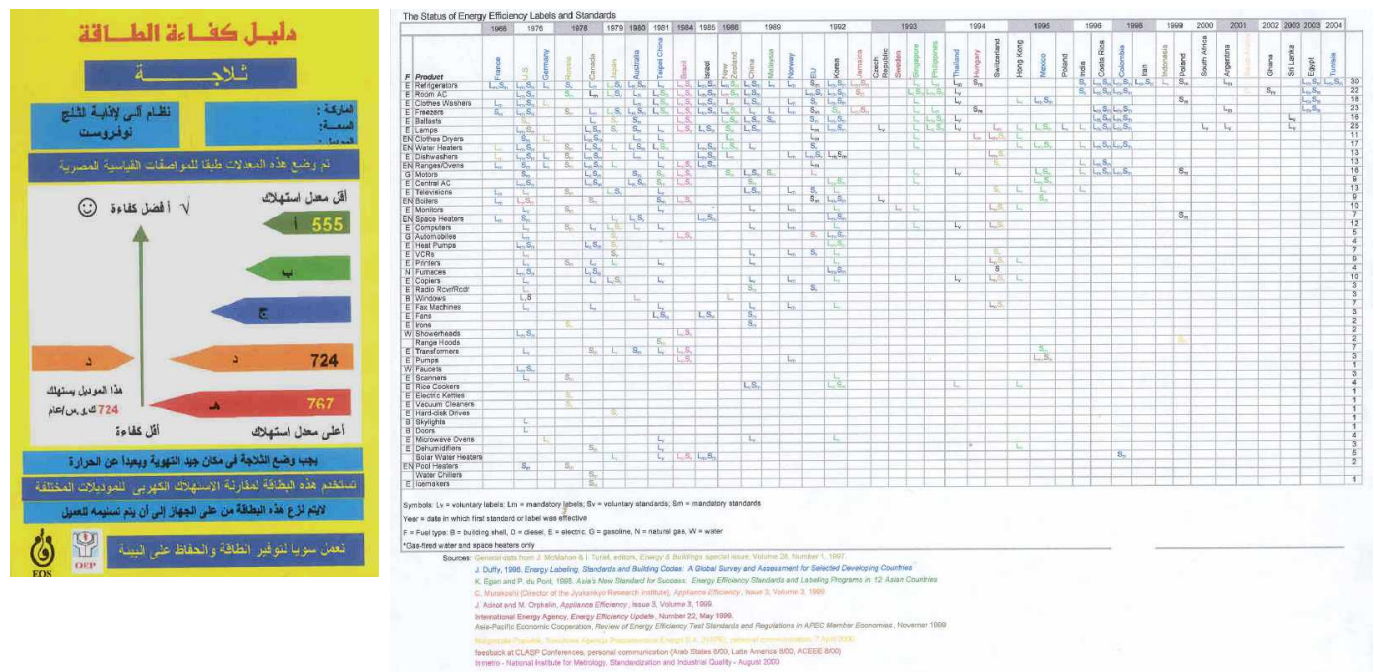

Some of these improvement options have been applied at some refrigerators manufacturing plants and lead to the following energy savings.

The energy efficiency standards for the three appliances have been developed including testing and certification methods. The labels have been elaborated and selected based on surveys.

In 15/10/2002 the Minister of Industrial and Technology Development issued a ministerial decree to enforce the application of energy efficiency specifications for the three selected appliances.

The Government of Egypt had succeeded in obtaining a fund from the UNDP Thematic Trust Fund for the establishment of an accredited energy efficiency testing laboratory to support the national energy efficiency standards and labeling program. This fund has been utilized to upgrade the existing testing facility at the New and Renewable Energy Authority (NREA) in order to be capable of performing necessary energy efficiency tests

The accredited Energy Efficiency Testing Laboratories have been erected for Refrigerators, Washing Machines, air conditioners and efficient lighting equipment has been completed.

Energy Efficient Design and Construction for New Buildings: 
Despite the considerable energy savings available; designers, builders and owners of buildings are either unaware or not interested in selecting building designs that reduce energy requirements, due to the fact that many energy efficiency design features have a higher initial cost.

On other hand there are no energy efficiency standards for building construction in Egypt. The project has focused on developing and applying a code of practice for energy efficient design in newly constructed residential and commercial buildings, and setting a plan for implementation and enforcement of this code.

One of the main objectives of the project is energy efficiency in buildings; it is to be realized through the development of an energy efficient code for Residential and Commercial buildings. This objective has been assigned to the Housing and Building Research Center (HBRC) of the Ministry of Housing. To fulfill the objectives, the activities were split into two resembling paths one for developing the residential code and the second for developing the commercial code. The two activity groups are performed in cascade, with 6 month overlap. Each objective includes five main activities

- Revision of codes of countries with similar conditions, and development of the Egyptian code skeleton (outline)

- Survey of buildings and equipments and selection of a base case for different building categories in Egypt.

In January 2006 a Ministerial Decree was issued by the Ministry of Housing Utilities \& Urban Communities for the enforcement of the Residential Building Energy Efficiency Code,

The final draft code for Commercial and administrative buildings will be presented in a public review in the 1st half of 2008 for finalization in order to issue the ministerial decree for their enforcement.

\section{Improving Energy Efficiency Program in Egyptian Governmental Buildings}

As the governmental sector is one of the high consuming sectors, reaching $4325 \mathrm{GWh}$ for the year 2003/2004 and amounting to 0.8 Billion L.E. it was decided to conduct a study aiming at recommending actions to be taken in order to implement energy efficiency measures in Egyptian governmental buildings.

In addition to the high consumption of EGBs, many other reasons led to the selection of the EGBs as a candidate for the study:

- The similarity of energy consumption patterns which support replication of feasible energy efficiency projects among governmental buildings.

- The existed electrical facilities are of old types and in many cases operate 

inefficiently.

- Procurements guidelines for new equipment in governmental buildings do not include energy efficient constrains or incentives.

- Lack of programs or efforts regarding raising the capabilities of the technical operators within EGBs on energy efficiency and energy conservation.

- Lack of awareness efforts directed to the employees occupying the EGBs regarding energy conservation practices.

Moreover, the electricity bills of most of the governmental buildings are paid partially by the administrative authority of the building according to their budget capabilities, the remaining of the electricity bills are paid by the Ministry of Finance through the annual settlement. This practice discourages any effort regarding improving energy efficiency or energy conservation.

The study was based on real consumption of all governmental buildings belonging to the different ministries, identification of energy consumption patterns, energy conservation opportunities and implementation of pilot projects.

The energy efficiency study on EGBs concluded three main clusters of recommendations on short, medium and long term implementation timeframe.

The short term recommendations include:

B Appointment of an energy manager for each governmental building provided with sufficient training, responsible for following up the energy conservation measures

ß Conducting awareness programs targeting the employees occupying the governmental buildings.

The medium term recommendations include:

Implementing retrofits of the current governmental building facilities especially for the lighting system, including replacement of incandescent lamps by the compact fluorescent lamps and using electronic ballasts instead of the magnetic ballasts, in addition of improving power factor for these buildings.

The long term recommendations concentrate on:

Developing governmental procurement guidelines to take into consideration energy efficiency concept. This stage will rely on the results and experience gained from the medium term recommendations.

The recommendations of this study have been presented by the Minister of Electricity \& Energy to a Ministerial committee which approved it and decide to start its application.

To encourage the application of such programs, the Ministry of Electricity \&Energy decided to start its implementation in the ministry buildings.

The Energy Efficiency Improvement \& Greenhouse Gas Reduction Project 
(implemented by the Ministry of Electricity \& Energy and funded by the UNDP and GEF) trough its own resources, will finance the application of energy efficiency projects in the electricity distribution companies buildings by selecting two buildings, in each company, as an example. The distribution companies will reimburse the cost to the project according to the pay back period, after which the cost of savings will be shared equally by the distribution company and the project. This will act as a revolving fund to implement more energy efficiency projects.

\section{Energy Efficiency Center:}

Energy efficiency markets need information that is: accessible, reliable, updated, and relevant. Without it, this market will be slow to emerge.

The energy efficiency center established within the project, and expected to sustain beyond the life time of the project, will act as information focal point and has the role of information provision, management, and dissemination.

This is currently achieved through:

- Developing an energy information data-base for the electricity big consumers, this database contains information about the big consumers as well as electrical and thermal information such as annual electrical consumption, peak demand, power factor, contracted demand, annual fuel consumption...etc. The big customer's data are regularly updated and indices are communicated to distribution companies for improving their performance

- Increase public awareness through information campaigns, publications, forums and newsletters.

- Developing a project website: www.eeiggr.org, which contains a description of the project, achievements, energy tips, energy audit analysis, seminars and workshops.

- Developing an information data base for the energy audits including the various technologies used such as efficient lighting, efficient motors, process control, boiler tune up, HVAC systems, management systems, insulation, convert to gas, cogeneration...etc as well as detailed information about the total savings, CO2 savings, investments and pay back periods.

\section{COMPONENT 3: Promotion of Co-generation}

The target of this component is to reduce $3 \%$ of the total energy consumption by the year 2010 resulting in reducing $\mathrm{CO} 2$ production by 3 million tons; This will be achieved through:

Establishment of Small Power Group within the Planning Department of EEHC Establish Safety and Interconnection Requirement for Parallel Grid Connection with 
Small Producers

Create an Infrastructure for EEHC to Purchase Electricity from Small Producers

Develop Industrial Co-generation and Agriculture Waste Projects for Small Power Production to introduce co-generation application, the project has created a small power group within EEHC's Planning Studies and Design Sector responsible for achieving this objective, up till now the following have been achieved:

Preparation of a legal framework for co-generation projects

Development of a power purchase agreement for small power producer.

Preparation of specification for required interconnection equipment.

Development of tariff structure for cogeneration.

Two demonstration projects were supposed to be implemented:

Co-generation pilot application in MOUT power plant at Dekhlah Oasis (remote isolated area)

Waste heat recovery application in an oriental resort at Sharm El sheikh. The oriental resort is a five stars resort located at Sharm El-Sheikh and relies for its power supply on an independent power producer (IPP) "Power House" through a BOO contract,

The techno-economic study of these projects have proved to be feasible but after the latest increase of fuel prices, the pay back period of these projects was doubled, this led to reconsidering their implementation.

A new approach was adopted for the interconnection of the existed cogeneration in the industrial sector to increase their loading capabilities this will be as an added cogeneration power.

An Agreement with Arab Contractors Co. is signed to develop the cogeneration unit at Alu Misr for its parallel operation with the grid.

A feasibility study for the parallel operation is carried out for testing the unit under loading conditions and identify ways to improve its current load factor of $57 \%$ to an increased targeted load factor of $80 \%$ after maintenance.

South Cairo D.C requested technical and financial offers from the specialized companies in the field of synchronization of the co generation units to implement the project.

Three technical and financial offers have been submitted and a team of experts from Alu Misr and Cairo South Distribution Company are analyzing the offers to select the best one.

It is expected that the project will be implemented in the 1st half of 2008 . 